\title{
Produits de niches et cultures de diversification : à la recherche de valeur ajoutée
}

Reçu le 10 septembre 2017 - Accepté le 29 septembre 2017

L'intérêt de la diversification en agriculture a déjà été abordée dans des précédents dossiers de la revue $O C L$, comme ceux consacrés aux filières lins et chanvre (OCL 22-6) ou encore ceux, plus transversaux, dédiés à l'agroécologie (OCL 24-3) et au changement climatique (OCL 24-1). Comme le rappelait André Merrien (Merrien, 2015), un des leviers d'amélioration de la durabilité de nos systèmes de cultures passe par un renforcement de leur diversification. Pour autant, un verrouillage sociotechnique autour des espèces majeures entrave le développement des cultures mineures et de leurs filières (Meynard et al., 2015). De nombreux acteurs entretiennent ce cercle vicieux pour des raisons diverses, auxquelles s'ajoute leur difficulté à se coordonner, comme le listait dans nos pages JeanMarc Meynard (Meynard, 2017): les sélectionneurs (peu d'investissement sur les espèces mineures, en raison d'un marché limité); les instituts techniques et chercheurs (peu d'études sur les espèces peu cultivées); les agriculteurs (peu d'informations sur ces espèces, sur la modification de leurs systèmes de culture pour les introduire...); les coopératives et négoces (petits qui compliquent leur logistique); l'agroindustrie (processus de transformation calés sur les espèces majeures); les distributeurs et les consommateurs (fidèles aux produits issus des espèces dominantes). D'où la difficulté à développer les cultures de diversification en France.

Dans ce nouveau dossier, nous proposons au lecteur un tour du monde via quelques exemples de diversification ou de développement de produits de niche. Le point commun de toutes ces initiatives : la recherche d'une valeur ajoutée, que ce soit en valorisant ce qui était un co-produit, en optimisant le rendement de l'extraction d'huile ou en qualifiant les acides gras des productions afin de mieux en cerner les débouchés potentiels.

Ainsi, l'extraction d'huile à partir de pépins de raisin issus de l'industrie vinicole (Pierron, 2017), l'extraction d'huile de noyau de mangue (Mas-ud et al., 2017) permettent de transformer un déchet en co-produit et d'en extraire une huile qui représente autant de valeur ajoutée.

Pour améliorer la rentabilité de ces petites productions, des optimisations sont recherchées d'un point de vue tant quantitatif que qualitatif. Dans l'article dédié à l'extraction de l'huile de noyau de mangue, l'équipe de Fajriyati Mas'ud (Mas-ud et al., 2017) a recherché une condition optimale d'extraction afin d'optimiser le rendement, la teneur en phénols (total phenolic content ou TPC) et en vitamine E. En Afrique, l'équipe de Thomas Silou (Silou et al., 2017) a travaillé à l'optimisation de la production à l'échelle artisanale, d'huile de palme rouge, riche en carotènes et à faible indice d'acide, dans le bassin du Congo. Enfin, se pose bien entendu la question des débouchés. En Asie, des chercheurs se penchent sur les caractéristiques physico-chimiques de l'huile de palme brute à haute teneur en acides gras libres pour en développer les applications dans la production de bioplastiques, biolubrifiants et biodiesel (Japir et al., 2017). Au Brésil, une autre équipe (Guedes et al., 2017) s'est intéressée à l'huile de péqui, un fruit de grande importance économique pour les familles de petites communautés de la région du Cerrado brésilien. Son huile contient $60 \%$ d'acide oléique et $35 \%$ d'acide palmitique, aptes à être utilisés en tant que matières grasses industrielles. En outre, la présence de triacylglycérols $\mathrm{POO}$ et $\mathrm{POP}$ confère à l'huile un intérêt particulier pour les industries cosmétiques et alimentaires.

Bien entendu, il ne s'agit que de quelques exemples. Pour autant, ils illustrent que les produits de niches et cultures de diversification peuvent trouver leur place, et ce d'autant plus facilement que la recherche travaille à en améliorer la performance économique et donc la valeur ajoutée.

\section{Références}

Guedes AMM, Antoniassi R, de Faria-Machado AF. 2017. Pequi: a Brazilian fruit with potential uses for the fat industry. OCL 24(5): D507.

Japir AA-W, Salimon J, Derawi D, Bahadi M, Al-Shuja'a S, Yusop MR. 2017. Physicochemical characteristics of high free fatty acid crude palm oil. OCL 24(5): D506.

Mas-ud F, Mahendradatta M, Laga A, Zainal. 2017. Optimization of mango seed kernel oil extraction using response surface methodology. OCL 24(5): D503.

Merrien A. 2015. Introduction. OCL 22(6): D601.

Meynard J-M. 2017. L'agroécologie, un nouveau rapport aux savoirs et à l'innovation. $O C L$ 24(3): D303.

Meynard JM, Messéan A, Charlier A, et al. 2015. La diversification des cultures: lever les obstacles agronomiques et économiques. Versailles: Éditions Quae, 106 p.

Pierron J-C. 2017. L'huile de pépins de raisin en France et dans le monde. OCL 24(5): D502.

Silou T, Moussounda-Moukouari R, Bikanga R, et al. 2017. Smallscale production in the Congo basin of low-acid carotene-rich red palm oil. OCL 24(5): D504.

Valérie Duflot contact@ocl-journal.org 